\title{
Infertility: an out-of-the-box cause of postmenopausal endometrial thickening
}

\author{
Ana Portela Carvalho, Isabel Meireles, Cristina Oliveira, Conceição Nunes
}

Department of Obstetrics and Gynaecology, Centro Hospitalar Tâmega e Sousa, Penafiel, Portugal

\section{Correspondence to} Dr Ana Portela Carvalho, ana.sofia.portela.carvalho@ gmail.com

Accepted 23 March 2018

\section{DESCRIPTION}

The presence of intrauterine foreign bodies (IFBs) is a rare condition that may lead to chronic endometritis through local inflammation. According to literature, IFB may be the cause of $0.02 \%$ to $0.15 \%$ of the cases of infertility, and of abnormal uterine bleeding, pelvic pain and abnormal vaginal discharge. ${ }^{1}$

We present the case of a 63-year-old, nulligravida, postmenopausal woman who complained of scarce genital bleeding and vaginal discharge for about 1 year. The patient denied other symptoms like fever, pelvic pain, dyspareunia or weight loss. In terms of relevant previous history, this patient had a laparotomy and myomectomy performed 30 years before because of a transmural uterine leiomyoma diagnosed in the workup for primary infertility. Even after surgery, no pregnancy was achieved. Menopause occurred at 52 years of age and no hormonal replacement therapy was used. No other relevant previous medical or surgical history was found.

On pelvic examination, a light uterine bleeding was identified and the remaining physical findings were normal. A pelvic transvaginal ultrasonography was performed and a $3 \mathrm{~cm}$ leiomyoma, a $7 \mathrm{~mm}$ endometrial thickening and hydrometra were identified (figure 1).

The patient underwent an office hysteroscopy that revealed endometrial atrophy, presence of mucus and an IFB compatible with a non-absorbable, synthetic, braided polyester surgical thread (figure 2A). The surgical thread protruded from the fundal uterine wall to the uterine cavity, erroneously suggesting an endometrial thickening at the ultrasound (figure 2B). It was mechanically excised with scissors and grasping forceps. Endometrial

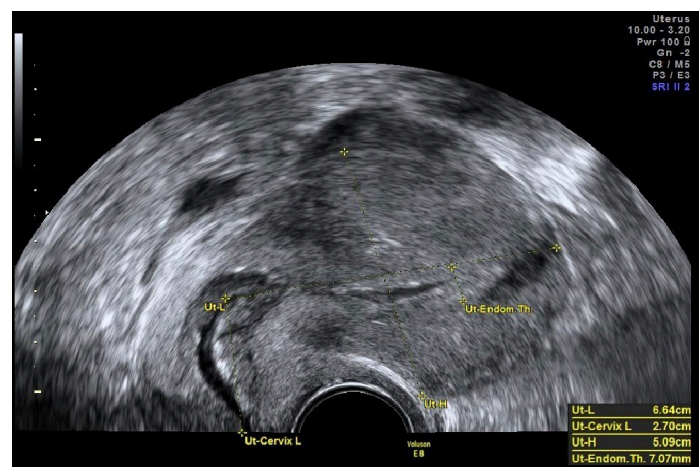

Figure 1 Pelvic transvaginal ultrasonography showing a $3 \mathrm{~cm}$ leiomyoma, a $7 \mathrm{~mm}$ endometrial thickening and hydrometra.

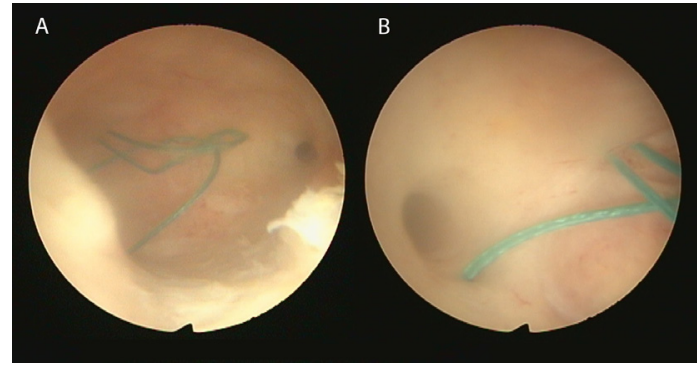

Figure 2 Hysteroscopy images revealing a nonabsorbable synthetic surgical thread $(A)$ that protruded from the fundal uterine wall to the uterine cavity (B).

biopsies were performed and histology of the specimens had no evidence of hyperplasia or malignancy. At follow-up visit 6 months later, the patient was asymptomatic.

Postmenopausal uterine bleeding is always abnormal and requires further investigation. The most frequent cause is the endometrial atrophy due to oestrogen deficiency characteristic of menopause. Nevertheless, $10 \%$ of these patients have endometrial malignant or premalignant lesions. ${ }^{2}$ The association between abnormal uterine bleeding

\section{Patient's perspective}

Postmenopausal vaginal bleeding is always an alarming situation due to the fear of an unknown genital cancer. So, the exclusion of malignancy is reassuring. However, discovering 30 years later that the possible cause of my infertility was a non-absorbable surgical thread was a shocking surprise! Thankfully, medicine improved considerably, and the identification and treatment of this type of condition is easily done using, fast, simple, and non-invasive procedures.

\section{Learning points}

- Postmenopausal uterine bleeding in the setting of ultrasonographic endometrial thickening requires further investigation and endometrial biopsy.

- Intrauterine foreign bodies are a rare but treatable cause of infertility.

- Hysteroscopy is an essential tool for endometrial study both in abnormal uterine bleeding and infertility. 
and endometrial thickening on transvaginal ultrasound requires histological biopsy.

In this case, the unusual hysteroscopic finding of an intrauterine non-absorbable surgical thread remaining from a myomectomy performed 30 years before explains the symptoms.

Non-absorbable synthetic surgical material in the uterine cavity has been described in literature as a rare cause of infertility. ${ }^{3}$ Intrauterine surgical thread might have behaved as a non-reversible intrauterine device, inducing a local inflammatory reaction that disturbs the microenvironment of the uterine cavity and the endometrial receptivity to implantation. Years later, the ultrasonographic image of the surgical thread erroneously led to the suspicion of an endometrial thickening in a postmenopausal woman presenting with abnormal uterine bleeding. Hysteroscopy is then of major importance for the correct definitive diagnosis, and for the foreign body removal under direct visualisation.

To the best of our knowledge, this is the first reported case of infertility and postmenopausal bleeding secondary to an intrauterine non-absorbable synthetic thread used in a previous myomectomy.
Contributors APC wrote the manuscript and acquired the. data. $\mathrm{CO}$ acquired the data and provided critical revision of the manuscript. IM and CN provided critical revision of the manuscript.

Funding The authors have not declared a specific grant for this research from any funding agency in the public, commercial or not-for-profit sectors.

Competing interests None declared.

Patient consent Obtained.

Provenance and peer review Not commissioned; externally peer reviewed.

(c) BMJ Publishing Group Ltd (unless otherwise stated in the text of the article) 2018. All rights reserved. No commercial use is permitted unless otherwise expressly granted.

\section{REFERENCES}

1. Makris N, Stefanidis K, Loutradis D, et al. The incidence of retained fetal bone revealed in 2000 diagnostic hysteroscopies. JSLS 2006;10:76-7.

2. van Hanegem N, Breijer MC, Khan KS, et al. Diagnostic evaluation of the endometrium in postmenopausal bleeding: an evidence-based approach. Maturitas 2011;68:155-64

3. Grigore M, Blidaru I, lordache F. Intrauterine foreign bodies, other than contraceptive devices and systems, may affect fertility - report of two very different cases. Eur $J$ Contracept Reprod Health Care 2014;19:141-3.

Copyright 2018 BMJ Publishing Group. All rights reserved. For permission to reuse any of this content visit http://group.bmj.com/group/rights-licensing/permissions.

BMJ Case Report Fellows may re-use this article for personal use and teaching without any further permission.

Become a Fellow of BMJ Case Reports today and you can:

- Submit as many cases as you like

- Enjoy fast sympathetic peer review and rapid publication of accepted articles

- Access all the published articles

- Re-use any of the published material for personal use and teaching without further permission

For information on Institutional Fellowships contact consortiasales@bmjgroup.com

Visit casereports.bmj.com for more articles like this and to become a Fellow 